\title{
In-Hospital Glucose Monitoring: Adequacy and Resource Management
}

\author{
Cesare Berra*, Elena Azzolini, Federico Zangrandi, Marco Mirani, Marco Albini, Francesco De Fazio, \\ Giuseppe Favacchio, Nicole Mauer and Patrizia Meroni \\ Humanitas Clinical \& Research Center Rozzano, Italy
}

Received: June 11, 2018; Published: June 21, 2018

*Corresponding author: Cesare Berra, Humanitas Clinical \& Research Center Rozzano, Italy

\begin{abstract}
Adequate capillary glucose monitoring in the inpatient population is of crucial importance, as poor glucose control is associated to higher morbidity and mortality. In our experience, this practice does not always parallel clinical urgency, nor is it correlated to an immediate intervention leading to a treatment modification. We analyzed all capillary glucose data documented in the Electronic Medical Records of all hospitalized patients (excluding intensive care patients) during the first semester of 2015. Subsequently, a glucose monitoring protocol was devised, based on inpatient clinical characteristics, which we shared with medical and nursing staff with the aim of optimizing resources and standardizing measurement practices in our hospital.

All capillary glucose was analyzed in the first semester of 2016 after adopting the proposed protocol. Less hypoglycemic episode was founded. Sensitizing and educating staff on the topic of glycemia may lead to clinical improvements, potentially reducing the risk of infection, as well as reducing the duration of hospitalization and impacting clinical management positively in a comprehensive manner. An adequate and systematic utilization of capillary glucose data as decisional aid tool, eventually to be integrated with an 'alert' system, may become a valid pillar of support in the planning and improvement of inpatient care available to healthcare professionals.
\end{abstract}

Keywords: Glucose Monitoring, Hospitalization, Resource Management

\section{Introduction}

According to the 2010 ISTAT report diabetes (type 1 and 2) is documented as primary or secondary diagnosis in $6 \%$ of the inpatient population [1]. The prevalence of diabetes can however significantly vary across different units. For instance, emergency ward inpatients display a higher prevalence of approximately $22-24 \%$ $[2,3]$. Another study conducted in 2014 in Italy suggests that approximately $23 \%$ of diabetic patients are hospitalized at least once a year compared to $11 \%$ of unaffected subjects [4]. Among health care expenditures attributable to metabolic disease the hospitalization of diabetic subjects produces the highest costs [5,6]. Hyperglycemias at admission, regardless of previous diagnosis of diabetes, is associated to higher morbidity and mortality across all areas of care $[7,8]$. Glucose monitoring in these patients or in patients at risk of developing hyperglycemias is therefore crucial. A recent metanalysis involving aprox. 15 important studies confirmed that adequate blood glucose control $(<150 \mathrm{mg} / \mathrm{dl}$ or $8.3 \mathrm{mmol} / \mathrm{L}$ ) featuring the use of specific protocols in the preoperative setting significantly reduced the risk of surgical infections [9] and that a radical intervention aimed at correcting hyperglycaemia in subjects at risk resulted in lower mortality and morbidity [10]. There are numerous studies and validated glucose managing protocols for the management of critical care patients (ranging from the DIGAMI study to more recent observations in CRIT CARE). However, little is known about the management of diabetic patients in regular wards.

\section{Aim of Study}

There is a lack of capillary glucose monitoring protocols for the management of hospitalized patients containing precise and strict instructions related to pathology (diabetes) and individual therapy in scientific literature. According to SID-AMD 2016 guidelines for patients in stable conditions, who are not receiving oral nutrition measurement intervals of indicatively 4 to 6 hours, are acceptable [11]. In contrast, patients feeding orally require measurements before meals and before sleep, as well as the possibility of adding postprandial and nightly measurements too. Intermittent, occasional measuring practices followed by insulin administration 'as required' in that moment (sliding scale) are to be avoided because considered inadequate and inefficient [12]. In all patients not considered diabetic but who are receiving treatments that entail a hyperglycaemic risk (such as high dosage steroids, enteral or parenteral nutrition, drugs like octreotide or immunosuppressant's) glucose monitoring must be recommended in order to potentially supply corrective insulin injections or to implement a basal-bolus scheme in case of persisting hyperglycaemias. 
Nevertheless, in daily clinical practice the completion of capillary glucose measurements depend on the demands of a ward (available resources and type of inpatients), which can be highly variable (medical vs. surgical wards; acute vs. subacute; arrangements with medical staff vs. competence of nursing staff) and does not necessarily match actual clinical needs, nor does it correlate with an immediate intervention leading to a treatment modification. The presence of hypoglycemia's and hyperglycaemias does not always result in immediate therapeutic actions leaving the hospitalized patient exposed to the risks of glycaemic variability before therapy is eventually adjusted. The lack of a universally shared protocol for the adequate metabolic management of patients results in an underestimation of the problem, the above-mentioned repercussions as well as wasteful use of resources. The aim of our study was to hence to conceive a glucose monitoring protocol based on inpatient characteristics, and to share it with all medical, nursing and paramedical hospital staff with the aim of optimizing and homogenizing the collection of these data. We further attempted to evaluate the impact of protocol implementation on the total number of measurements performed and, considering the crucial importance of glycaemia, on the number of total hypoglycemia's and hyperglycaemias.

\section{Materials and Methods}

Humanitas Research Centre is a highly specialized hospital with 747 beds, of which 651 ordinary beds distributed across 15 wards. From January 2015 all admitted patients are managed via Electronic Medical Records (wHospitalTM). Vital parameters, including capillary glucose measurements are reported in a specific section of the records. A standard measuring system (ACCU-CHECK Aviva $\rightarrow$ Roche) is used for capillary glucose measurements across all wards, the system itself being validated by a centralized control protocol. We collected all capillary glucose values from patient records between $1^{\text {st }}$ January and $30^{\text {th }}$ June 2015 in all wards, excluding intensive care and sub-intensive care areas. The frequency of hyperglycaemias and hypoglycaemias was established, using cut off values of $>250 \mathrm{mg} / \mathrm{dl}$ and $<70 \mathrm{mg} / \mathrm{dl}$ respectively. We further determined how many of the patients had a recent glycated haemoglobin measurement available.

Table 1: Interventional protocol tailored to inpatient characteristics.

In-patients glucose monitoring (except intensive care areas)

\begin{tabular}{|c|c|c|c|}
\hline $\begin{array}{l}\text { Non diabetic } \\
\text { subject treated } \\
\text { with steroids }\end{array}$ & $\begin{array}{l}\text { Fasting capillary glucose } \\
\text { and post prandial }\end{array}$ & $\begin{array}{l}\text { 07:00 AM } \\
\text { 03:00 PM }\end{array}$ & $\begin{array}{l}\text { Every other } \\
\text { days }\end{array}$ \\
\hline $\begin{array}{c}\text { Diabetic subject } \\
\text { in oral treat- } \\
\text { ment }\end{array}$ & $\begin{array}{c}\text { Fasting capillary glucose } \\
\text { post prandial and before } \\
\text { evening meal }\end{array}$ & $\begin{array}{l}\text { 07:00 AM } \\
\text { 03:00 PM } \\
\text { 07:00 PM }\end{array}$ & $\begin{array}{l}\text { Every other } \\
\text { days }\end{array}$ \\
\hline $\begin{array}{l}\text { Diabetic subject } \\
\text { insulin treated }\end{array}$ & $\begin{array}{c}3 \text { times daily before } \\
\text { meals }\end{array}$ & $\begin{array}{l}\text { 07:00 AM } \\
\text { 07:00 AM } \\
\text { 07:00 PM }\end{array}$ & Every days \\
\hline $\begin{array}{l}\text { frail/high risk } \\
\text { subject insulin } \\
\text { treated }\end{array}$ & $\begin{array}{l}\text { strict capillary glucose } \\
\text { monitoring }\end{array}$ & $\begin{array}{l}\text { 07:00 AM } \\
\text { 12:00 AM } \\
\text { 03:00 PM } \\
\text { 07:00 PM } \\
\text { 10:00 PM }\end{array}$ & Every days \\
\hline
\end{tabular}

An interventional protocol tailored to inpatient characteristics was subsequently proposed, establishing the number of blood glucose measurements to be performed according to the following criteria (Table 1).Non-diabetic subject treated with steroids check fasting capillary glucose once in the morning and 2 hours after lunch on alternate days (7 am and $3 \mathrm{pm}$ ). Diabetic subject treated with oral hypoglycemic drugs check fasting capillary glucose once in the morning, 2 hours after lunch and before dinner on alternate days (7 am - 3 pm - 7 pm). Diabetic subject treated with insulin check capillary glycaemia daily, 3 times a day before meals. Diabetic frail/high risk subject treated with insulin perform strict capillary glucose monitoring (7 am- 11 am- 15 pm- 19 pm- 22 pm). Glucose measurement whenever symptoms compatible with insurgence of a hypoglycemic episode present. After gaining approval from the hospital management committee, the protocol was shared with all medical and nursing staff across wards during a series of formative courses. The protocol was subsequently introduced throughout our hospital, taking effect in all wards starting from admission and being managed directly by the nursing staff.

Six months after the implementation of the protocol capillary glucose data were once again analyzed, using glucose measurements collected during this period, with particular attention for values of hypoglycemia's and hyperglycaemias and evaluation of satisfaction in the staff responsible for protocol implementation. A two-sample t test with stable variance was used to compare the mean number of hypoglycemic and hyperglycemic episodes, as well as to inspect the proportion of patients with hypo/hyperglycaemias amongst the patients with at least one available glucose measurement; a two-sample test for proportions was used. Both tests were carried out using the STATA software.

\section{Discussion of Results}

In the period analyzed before the introduction of our protocol (first semester of 2015) 3440 subjects underwent at least 1 capillary glucose measurement, of which $46 \%$ had more than 4 daily measurements taken (retrospective evaluation). Among the subjects who underwent monitoring, 1649 hypoglycemic episodes ( $<70 \mathrm{mg} / \mathrm{dl}$ ) were detected in a total of 706 subjects and 9666 hypoglycemic episodes ( $>250 \mathrm{mg} / \mathrm{dl}$ ) in a total of 1424 patients (Table 2). The protocol was implemented from 1st January 2016. During the first semester of that year 3713 subjects were monitored, however the percentage of subjects undergoing more than 4 daily measurements dropped to $38 \%$. The frequency of hypoglycemic episodes was of 974 in 438 subjects, while 7266 hyperglycaemias were observed in 1020 subjects (Table 3).

Table 2: Altered glucose values in first semester 2015.

\begin{tabular}{|c|c|}
\hline Number of subjects undergoing monitoring & 3440 \\
\hline Number of subjects with value $<70 \mathrm{mg} / \mathrm{dl}<70 \mathrm{mg} / \mathrm{dl}$ & 1649 \\
\hline Number of subjects with value $<70 \mathrm{mg} / \mathrm{dl}$ & 706 \\
\hline Number of subjects with value $>250 \mathrm{mg} / \mathrm{dl}$ & 9666 \\
\hline Number of subjects with value $>250 \mathrm{mg} / \mathrm{dl}$ & 1424 \\
\hline
\end{tabular}


Table 3: Altered glucose values in first semester 2016.

\begin{tabular}{|c|c|}
\hline Number of subjects undergoing monitoring & 3713 \\
\hline Number of value $<70 \mathrm{mg} / \mathrm{dl}$ & 974 \\
\hline Number of subjects with value $<70 \mathrm{mg} / \mathrm{dl}$ & 438 \\
\hline Number of subjects with value $>250 \mathrm{mg} / \mathrm{dl}$ & 7266 \\
\hline Number of subjects with value $>250 \mathrm{mg} / \mathrm{dl}$ & 1020 \\
\hline
\end{tabular}

The reduction in percentage of patients with glucose measurements $>250 \mathrm{mg} / \mathrm{dl}$ or $<70 \mathrm{mg} / \mathrm{dl}$ out of those with an available capillary glucose measurement was found to be statistically significant $(\mathrm{p}<0.0001)$. The mean number of hypoglycemic episodes per patient was slightly reduced (2.22 vs. 2.34 ), but statistically insignificant $(p=0.2244)$. On the contrary, the mean number of hyperglycaemic episodes rose (7.1 vs. 6.8) in a statistically significant fashion $(p=0.0019)$. Nursing staff were interviewed to evaluate the level of satisfaction related to the implementation of the protocol (mainly dissatisfied, indifferent, very satisfied) and $84 \%$ declared to be very satisfied (data not shown).

\section{Conclusion and Potential Areas of Improvement}

Adequate metabolic management of hospitalized diabetic patients constitutes a critical aspect of care and must be kept in consideration as such $[13,14]$. Several clinical parameters are used as predictive outcomes in hospitalized patients, but glycaemia cannot be currently considered one of them $[15,16]$. In our hospital capillary glucose monitoring in different wards was previously not governed by a universal protocol and, except for intensive care areas, measurements were frequently not followed by therapeutic attempts aimed at avoiding or reversing potentially dangerous glucose value excursions in the hospitalized subject (glycaemic variability). In absence of precise guidelines concerning capillary glucose monitoring in the hospital setting also the inadequate utilization of hospital resources, in terms of both materials and workforce, cannot be corrected. Following the introduction of a capillary glucose monitoring protocol, hence also a metabolic control tool, a slight incrementation in glycaemic measurement practices has been observed, as well as a statistically non-significant reduction in hypoglycaemic episodes.

Conversely, a statistically significant incrementation in hyperglycaemias was encountered due to the lack of specialist interventions (such as consultations and/or protocols for the adaptation of therapy) to tackle these elevated blood glucose levels, most likely in previously unknown cases (iatrogenic diabetes?). The creation of a shared protocol, accompanied by the correct training of staff, can result in the optimization of resources without negatively impacting the clinical outcome of a patient. We believe that sensitizing and educating staff on the topic of glycemia may lead to clinical improvements, potentially reducing the risk of infection, as well as reducing the duration of hospitalization and impacting clinical management positively in a comprehensive manner. The intro- duction of a 'warning' signal triggered by severe hypoglycaemias or hyperglycaemias inside patient electronic medical records, for the responsible consultant to access, is currently underway. The Diabetology team will also receive these notifications to achieve a faster and more adequate clinical response to metabolic alterations in hospitalized subjects.

\section{References}

1. www.istat.it/it/archivio/71090

2. Plummer MP, Bellomo R, Cousins CE, Annink CE, Sundararajan K, et al. (2014) Dysglycaemia in the critically ill and the interaction of chronic and acute glycaemia with mortality. Intensive Care Med 40(7):973-8.

3. Ali Abdelhamid Y, Kar P, Finnis ME, Phillips LK, Plummer MP, et al. (2016) Stress hyperglycaemia in critically ill patients and the subsequent risk of diabetes: a systematic review and meta-analysis. Crit Care 20: 301.

4. De Berardis G, D’Ettorre A, Graziano G, Lucisano G, Pellegrini F, et al. (2012) DADA (Diabetes Administrative Data Analysis) Study Group. The burden of hospitalization related to diabetes mellitus: a populationbased study. Nutr Metab Cardiovasc Dis 22(7): 605-612.

5. Umpierrez GE (2014) Inpatient dysglycemia and clinical outcomes: association or causation? J Diabetes Complicatins 28(4): 427-429.

6. Ozieh M, Bishu KG, Dismuke CE, Egede LE (2015) Trends in health care expenditure in US adult with diabetes: 2002-2011. Diabetes Care 38(10): 1844-1851.

7. Umpierrez GE, Isaacs SD, Bazargan N, You X, Thaler LM, et al. (2002) Hyperglicemia: an indipendent marker of in-hospital mortalitiy in patients with undiagnosed diabetes. J Clin Endocrin Metab 87(3): 978982.

8. Inzucchi SE, Bergenstal RM, Buse JB, Diamant M, Ferrannini E, et al. (2015) Management of hyperglycemia in type 2 diabetes, 2015: a patient-centred approach. Diabetes Care 38(1): 140-149.

9. de Vries FE, Gans SL, Solomkin JS, Allegranzi B, Egger M, et al. (2017) Meta-analysis of lower perioperative blood glucose target levels for reduction of surgical-site infection. BJS 104: e95-e105.

10. Van Den Berghe G, Wouters P, Weekers F, Verwaest C, Bruyninckx F, et al. (2001) Intensive insulin therapy in critically ill patients. NEJM 345(19): 1359-1367.

11. Standard Italia per la cura del Diabete Mellito 2014 AMD SID 2014.

12. Queale WS, Seider AJ, Brancati FL (1997) Glycemic control and sliding scale insulin use in medical in patients with diabetes mellitus. Arch Intern Med 157(5): 545-552.

13. McDonnell ME, Umpierrez GE (2012) Insulin therapy for the management of hyperglycemia in hospitalized patients. Enocrinol Metab Clin North Am 41(1): 175-201.

14. Wang CCL, Drazinin B (2013) Pratical approach to management inpatient hyperglycemia in selected populations. Hospital Practice 41(2): 45-53.

15. Mendez CE, Mok K, Ata A, Tanenberg RJ, Calles-Escadon J, et al. (2013) Increased glycemic variability is independently associated with length of stay and mortality in noncritically ill hospitalized patients. Diabetes Care 36(12): 4091-4097.

16. Takeishi S, Mori A, Hachiyca H, Yumura T, Ito S, et al. (2016) Hypoglycemia and glycemic variability are associated with mortalitiy in non-intensive care unit hospitalized infectious disease patients with diabetes mellitus. J Diabetes Investig 7(3): 429-435. 
(c) (i) This work is licensed under Creative Submission Link: https://biomedres.us/submit-manuscript.php

\begin{tabular}{ll} 
BIOMEDICAL & Assets of Publishing with us \\
RESEARCHES & - Global archiving of articles \\
& - Immediate, unrestricted online access \\
& - Rigorous Peer Review Process \\
\hline
\end{tabular}

